\title{
Design and implementation of digital controller for DC-DC boost converter
}

\author{
Muaz Zabir bin Mohammad Suhaimi", Ahmad Asri Abd Samat, Nor Salwa Damanhuri, Nor Azlan \\ Othman, I.H. Hamzah and M.H.Abdullah \\ Universiti Teknologi MARA, Cawangan Pulau Pinang, Kampus Permatang Pauh, 13500 Permatang Pauh, Malaysia
}

Received: 15-September-2020; Revised: 16-January-2021; Accepted: 20-January-2021

(C)2021 Muaz Zabir bin Mohammad Suhaimi et al. This is an open access article distributed under the Creative Commons Attribution (CC BY) License, which permits unrestricted use, distribution, and reproduction in any medium, provided the original work is properly cited.

\begin{abstract}
This paper presents a design and simulation of a DC/DC boost converter by implementing the digital controller. In this project, the user chooses the desired output voltage. The system will then automatically calculate the duty cycle and produce the pulse width modulation (PWM) signal according to that duty cycle. The PWM signal was injected into power MOSFET, and the desired output voltage was produced by varying the duty cycle. PWM was designed by using two methods: analog and digital. PWM generator was designed analogously using MATLAB / Simulink software, while the digital controller of the PWM was developed using the Verilog Hardware Description Language (HDL). The performance of both techniques was compared in terms of their steady-state and transient response. MATLAB/Simulink was also used to create test signals and software test benches for Verilog code to validate the effectiveness of the designed system. The system was tested by varying the duty cycles at $70 \%$. The control design, analysis, and simulation results were presented in this paper to confirm the digitally controlled boost converter's performance. It has also been tested for its effectiveness by being implemented in MATLAB/Simulink using the co-simulation process. The results between analog and digital controller of boost converter have been compared. Among these two systems, digital control was producing a better performance as compared to analog controller.
\end{abstract}

\section{Keywords}

Boost converter, Digital controller, Verilog HDL.

\section{Introduction}

Most electronic devices nowadays are equipped with switched-mode power supplies (SMPS) to power up the devices. SMPS is a type of power supply that converts its input from Alternating current (AC) or Direct current (DC) to required output voltage using semiconductor switching technique. Previously, most DC power supplies used linear regulators composed of a substantial step-down transformer, filter circuit to remove ripple, and some voltage regulator. The linear regulator's advantage is its simple design that only needs an input capacitor, output capacitor and some feedback resistors. Although it is cost-efficient, the continuous conducting transistor dissipates power in heat, resulting in low efficiency, wasted power and constant heat generation.

Nowadays, the application of green technology has been increasingly popular as it is pollution-free and environmentally friendly.

*Author for correspondence

12
Due to environmental concerns and technology advancement, renewable sources have been one of the popular choices [1-4].

One of the components in green technology is an electronic power conversion. The DC-DC converter is one type of power conversion used to convert the renewable source into the desired load. It changes the output voltage from one level to another level [5]. The boost converter is a type of Switch Mode Power Supplies (SMPS) that increases the input DC voltage into a higher output voltage by switching technique. It has better performance, a wide conversion range reduced components, lower cost, smaller size, and higher reliability. Its advantageous features were used extensively in electronic applications such as computers, phones, and battery chargers $[6,7]$. The increasing use of power conversion in electronic components required the engineer to design a converter that could excel in conversion efficiency, less cost, and noise intervention. The switching power is highly controllable and can monitor the 
system improvement in energy management performance [8].

Conventional boost converter uses analog to control the output voltage. Analog controller is inexpensive and straightforward to used. It is also very robust and has a dynamic range which means it is easier to avoid being limited by self-noise. Analog has been used for a long time and has been a tried and true method. It can produce stable power supplies and less tendency toward glitches. However, it comes with its downside. Analog has limited flexibility compare to digital. The parameter is fixed during design and cannot be changed accordingly with the application. The control usually restricts to one feasible reaction per parameter.

This project is done to overcome the problem of analog control as discussed. It is achieved by applying digital controls using Verilog HDL. The boost converter was designed using MATLAB/Simulink and a control algorithm for the boost converter was developed using Verilog HDL. Then the control algorithm was implemented into boost converter design and the result was compared. Simulation result verifies the effectiveness of the designed digital controlled boost converter over the analog controller. However, this project is limited to open-loop systems only. The system is only used to obtain the desired output voltage but the output voltage cannot be controlled if there is a change or interruption to the system.

\section{Literature review}

Traditionally, DC-DC converter used analog controller to control the desired output value. Analog controller is cheaper and easier to use. It is also very robust and has a dynamic range which means it is easier to avoid being limited by self-noise. However, analog controller has several disadvantages that can be solved by the digital controller. One of these is that it has a slow development process, which means it is difficult to do an accurate design. It is also very sensitive toward external influences. Besides, the implementation of advanced analog control is complicated. Thus, the digital controller was introduced into the DC-DC converter and has been preferred for several years. The digital controller is better than the analog controller as it can execute complicated control algorithms such as adaptive control and non-linear control at eased [9]. The digital controller is used extensively in the smart grid. The smart grid technology makes use of digital and analog information, as well as communication techniques, to come up with several technological features [10].

Certain shortcomings of analog controller seized by the digital controller and it offers certain advantages such as faster design process, the facility for integration with other digital systems, low power consumption compared to the analog controller, low sensitivity to external influence, better performance, less sensitive in environmental variations, better noise tolerance, improves process performance and is versatile in making changes to fulfill the required needs [11]. Advanced power management technology is based on the integration of power control and electronic system conversion functions with the digital controller. Conversion and control function which is complicated to solve by analog approach can be easily implemented digitally. Inherently, digital controllers have a lower tolerance to system changes in parameters and therefore control schemes that are impractical for analog consideration can be introduced. The main advantages of the digital approach from the digital device design point of view are that well-established and automated design tools can be used to shorten the design process [12].

Different hardware was introduced to allow the implementation of the digital control algorithm. Some of these are digital signal processing (DSP), Field Programmable array (FPGA) and Logic Controller (PLC) [13]. PLC is very expensive, and it may not respond toward time constraints, thus not suitable for power converters [14]. It is more appropriate to be applied in automation proposes such as electro-mechanical duty in industries. DSP offers reprogramming ability and multiple functions that vastly outweighed its speed and cost. DSP executes the instruction sequentially using the Central Processing Unit (CPU) [15]. It often used with 2-level inverter topologies, using a single carrier-based PWM strategy [16].

Implementation based on Field Programmable Gate Array (FPGA) offers different advantages in flexibility, low power consumption, speed, smaller devices, and significant parallelism. Using VHDL script, the control algorithm and coding is performed and implemented using Altera FPGA Board. The FPGA regulates the whole process and determines whether to increase or decrease the voltage according to the demand [17]. FPGAs can exceed the performance of general-purpose CPUs by several orders of magnitude and offer dramatically lower costs and time to market than ASICs [18]. The model 
can then be easily moved to another operation, incorporated with other digital systems, or adjusted to meet new requirements [19]. FPGA is a reconfigurable gate array logic circuitry matrix that can be modified as required by the user. Such logic blocks build a hardware implementation of a software application once designed and attached.

On the other hand, FPGA offers high flexibility as they can be upgraded by reprogramming the Verilog hardware description language (HDL) code parameter and offering low-cost implementation. FPGA supports parallel execution as well as a multicarrier strategy [20]. DSP is only suitable for sequential operation, and however, in reality, parallelism is more required. Thus FPGA becomes preferable [21].

In this paper, a digital system controlled for boost converter was implemented by using Verilog HDL. The boost converter was designed using MATLAB/Simulink, and a control algorithm for boost converter was developed using HDL. Then the control algorithm was implemented into boost converter design, and the result was compared. Simulation result verifies the effectiveness of the designed digital controlled boost converter over the analog controller.

\section{Methodology}

This project consists of designing and testing the digital controller of the boost converter.

\subsection{Boost converter configuration}

Figure 1 depicts the converter block diagram. The process function is as follows. A $24 \mathrm{~V}$ DC serves as the power source. The converter circuit will step up or boost up the input voltage into a desired output value. The digital system will transmit the control signal to the converter the desired value. For the simulation, the boost converter circuit will be implemented in MATLAB Simulink. The digital system will be synthesized with ModelSim PE Student Edition 10.4a.

Figure 2 shows the boost converter has two modes of operation, consist of Mode 1 and Mode 2 depending on the switch 'ON' and 'OFF' time. In Mode 1, the switch is turned $\mathrm{ON}$, and the inductor current rises, and the diode becomes reverse-biased at $0<t<D T s$. In Mode 2, the switch is turned $\mathrm{OFF}$, and the diode becomes forward biased at $\mathrm{DTs}<\mathrm{t}<\mathrm{Ts}$, where ' $\mathrm{D}$ ' is the duty ratio of the switch and $\mathrm{Ts}$ is the switching time.

By applying KVL, the following expression can be derived. When the transistor is switched $\mathrm{ON}$ in Mode 1:

$\Delta i=\frac{\left(V_{\text {in }}-V_{\text {Trans }}\right) T_{o n}}{L}$

When the transistor is switched OFF in Mode 2, the current as followed:

$\Delta i=\frac{\left(V_{o u t}-V_{\text {in }}+V_{D}\right) T_{\text {off }}}{L}$

By equating $\Delta i$ in equation (1) and (2), $V_{\text {out }}$ can be solved:

$\frac{\left(V_{\text {in }}-V_{\text {Trans }}\right) T_{\text {on }}}{L}=\frac{\left(V_{\text {out }}-V_{\text {in }}+V_{D}\right) T_{\text {off }}}{L}$

$V_{\text {in }}-V_{\text {Trans }} D=\left(V_{\text {out }}+V_{D}\right)(1-D)$

$V_{\text {out }}=\frac{V_{\text {in }}-V_{\text {trans }} D}{(1-D)}-V_{D}$

If the voltage drops across the transistor and diode were neglected, then:

$V_{\text {out }}=\frac{V_{\text {in }}}{1-D}$

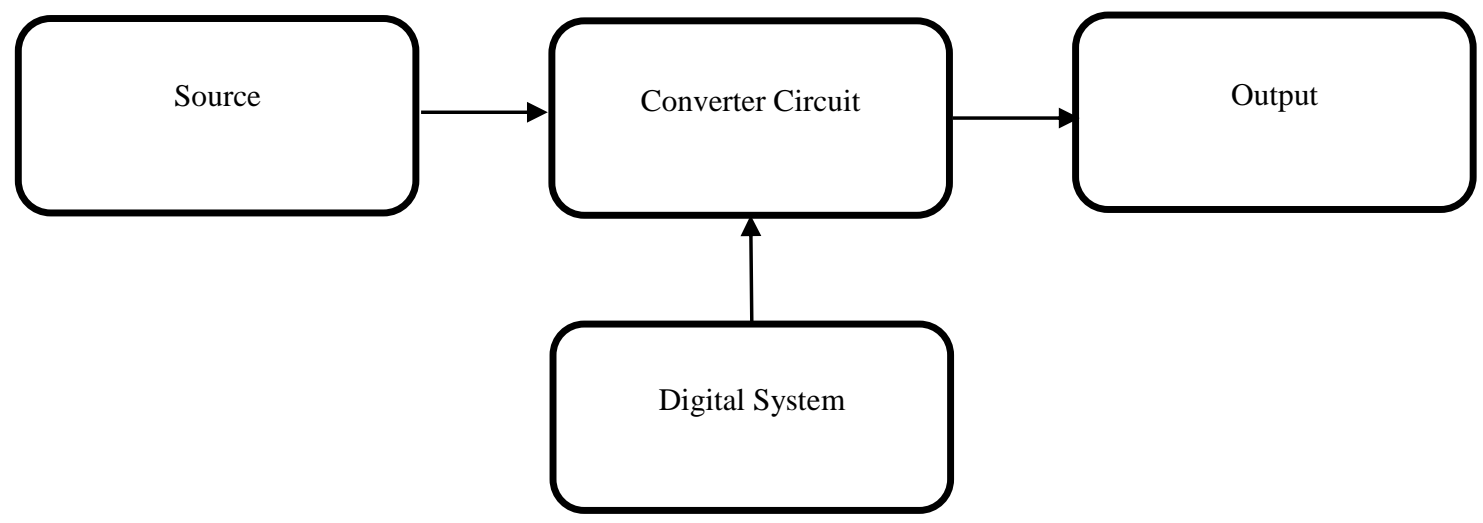

Figure 1 Simplified block diagram of a converter 


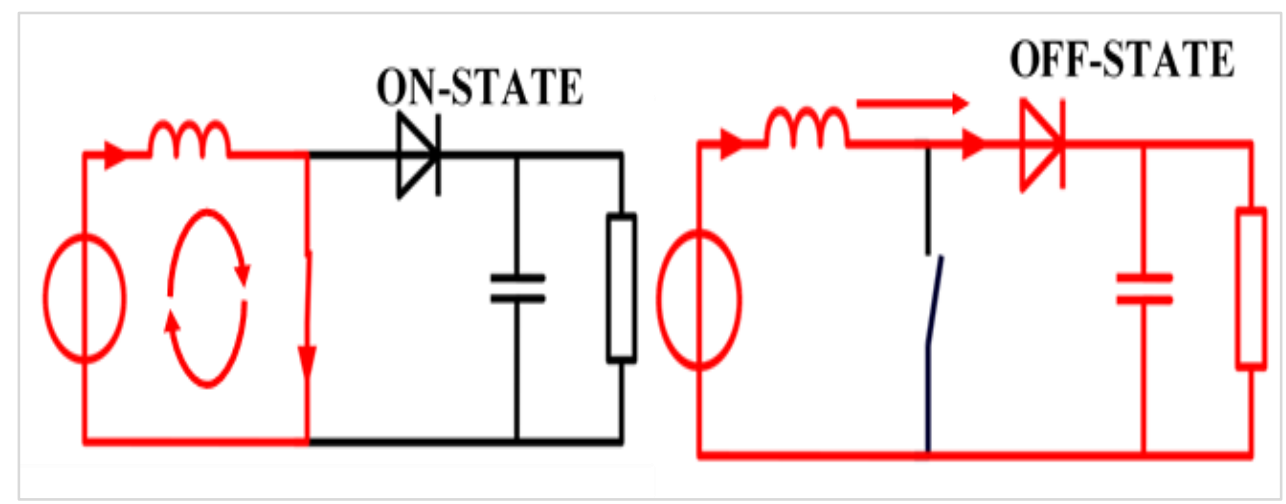

Figure 2 Boost converter circuit diagram with 2 modes of operation

All parameter can be derived from equation (3). Input voltage and duty cycle were determined to get the output voltage:

Load resistance $=\frac{V_{o}}{I_{o}}$

From equation (4), the value of current output $\left(I_{o}\right)$ was assumed to be 1.7 A to get the load resistance. $C=\frac{I_{o} \times D}{f_{s} \times \Delta V_{o}}$

The value of the capacitor was determined in equation (5).

$L=\frac{V_{S} \times D}{f_{S} \times \Delta I_{o}}$
Equation (6) was used to determine the value of the inductor. Table 1 tabulated the boost converter parameters used in this project. All the parameter values are derived from equations (1) to (6).

The switching controller used for analog is DC-DC PWM generator block from Simulink. The working principle for the generator is monitored by comparing the carrier counter ramp and input for the duty cycle to create the PWM output. The PWM generator block outputs either 1 when the duty cycle is greater than the carrier counter value, or 0 otherwise.

Table 1 Boost converter design parameters and values

\begin{tabular}{lll}
\hline Parameter & Nomenclature & Value \\
\hline Input Voltage & $V_{i}$ & $24 \mathrm{~V}$ \\
\hline Output Voltage & $V_{o}$ & $48 \mathrm{~V}$ \\
\hline Duty Cycle & $\mathrm{D}$ & $50 \%$ \\
\hline Capacitor & $\mathrm{C}$ & $200 \mathrm{e}-6 \mathrm{~F}$ \\
\hline Inductor & $\mathrm{L}$ & $220 \mathrm{e}-6 \mathrm{H}$ \\
\hline Load Resistor & $\mathrm{R}$ & $3 \Omega$ \\
\hline Switching Frequency & $\mathrm{Hz}$ & $20 \mathrm{kHz}$ \\
\hline
\end{tabular}

\subsection{MATLAB/Simulink implementation}

To verify that the design meets functional requirements, the boost converter is modelled in MATLAB/Simulink. The Simulink model of boost converter was created, as shown in Figure 3, with the design parameters tabulated in Table 1.

The system consists of two submodules: a calculation submodule in Figure 4 and a boost submodule in
Figure 5. The user can choose the desired output voltage, and the calculation submodule will automatically calculate the required duty cycle. The duty cycle value will be the input to the Pulse Width Modulator (PWM), and the PWM signal will be injected into the power MOSFET. Then, the boost converter will change the output voltage based on the PWM signal's duty cycle. 


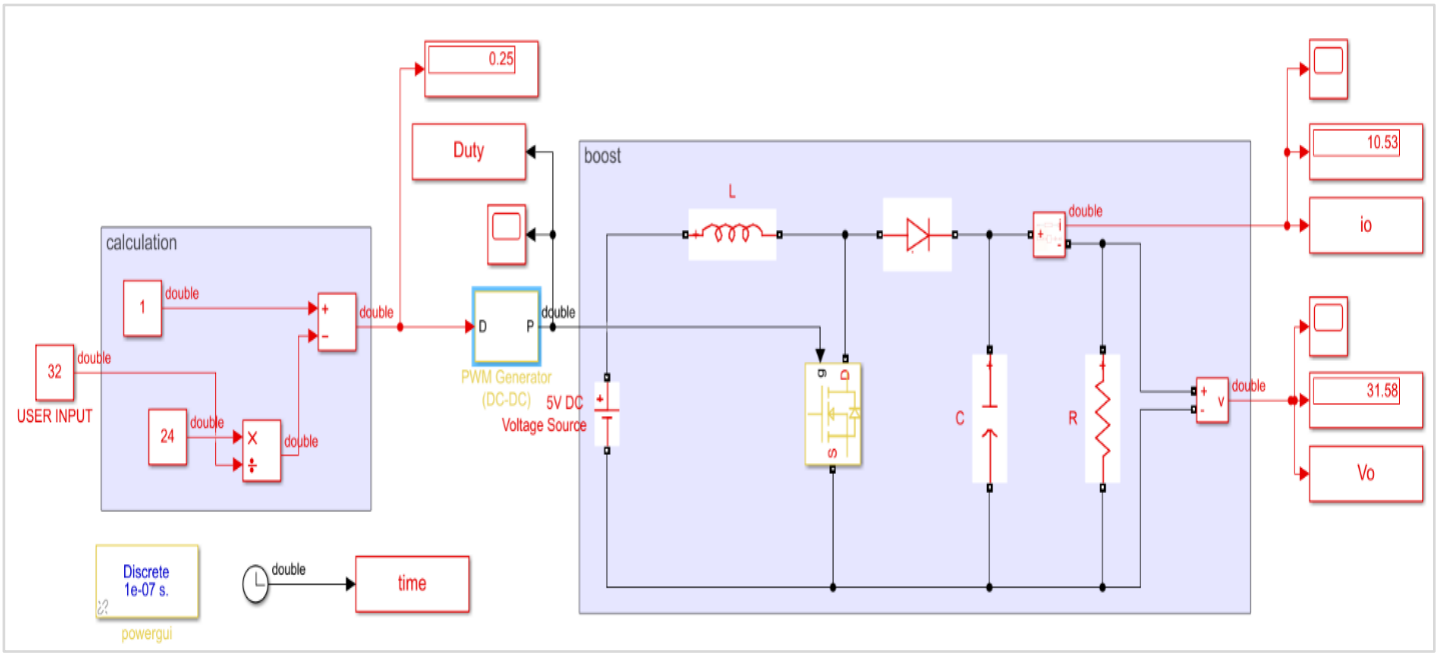

Figure 3 The boost converter block diagram constructed in Simulink

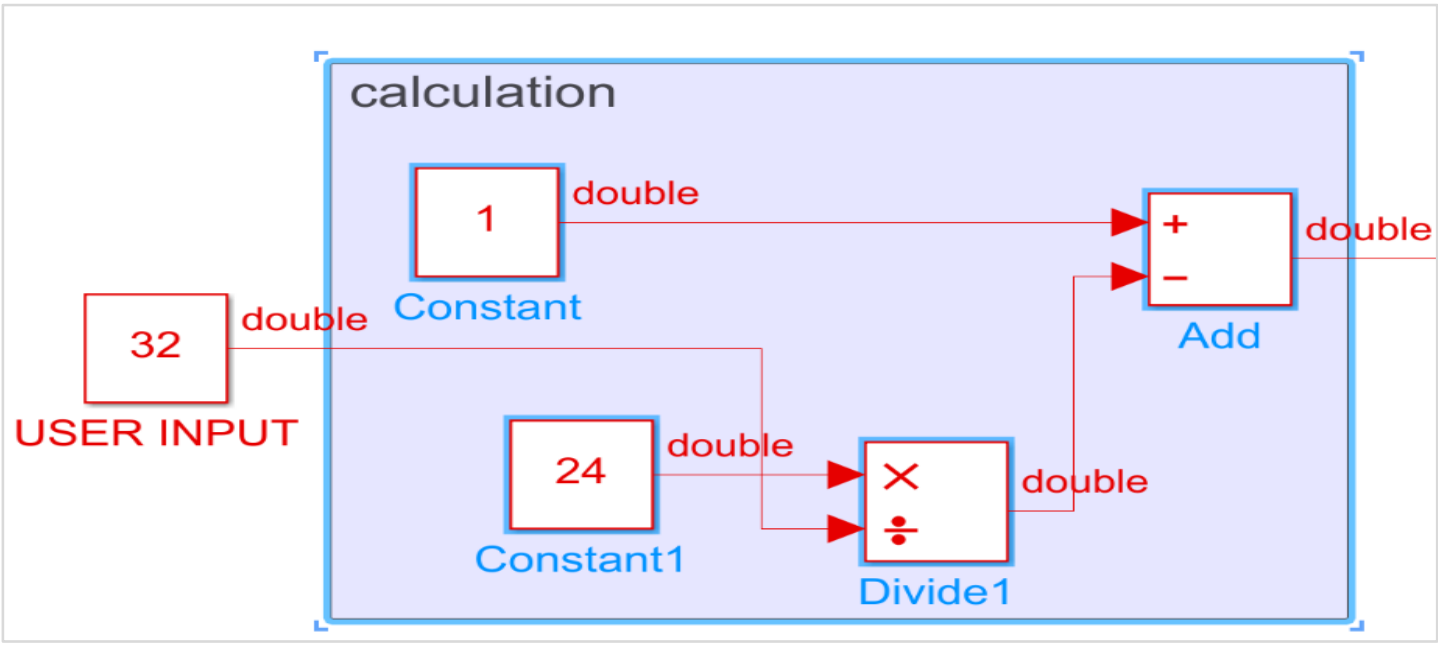

Figure 4 Calculation submodule

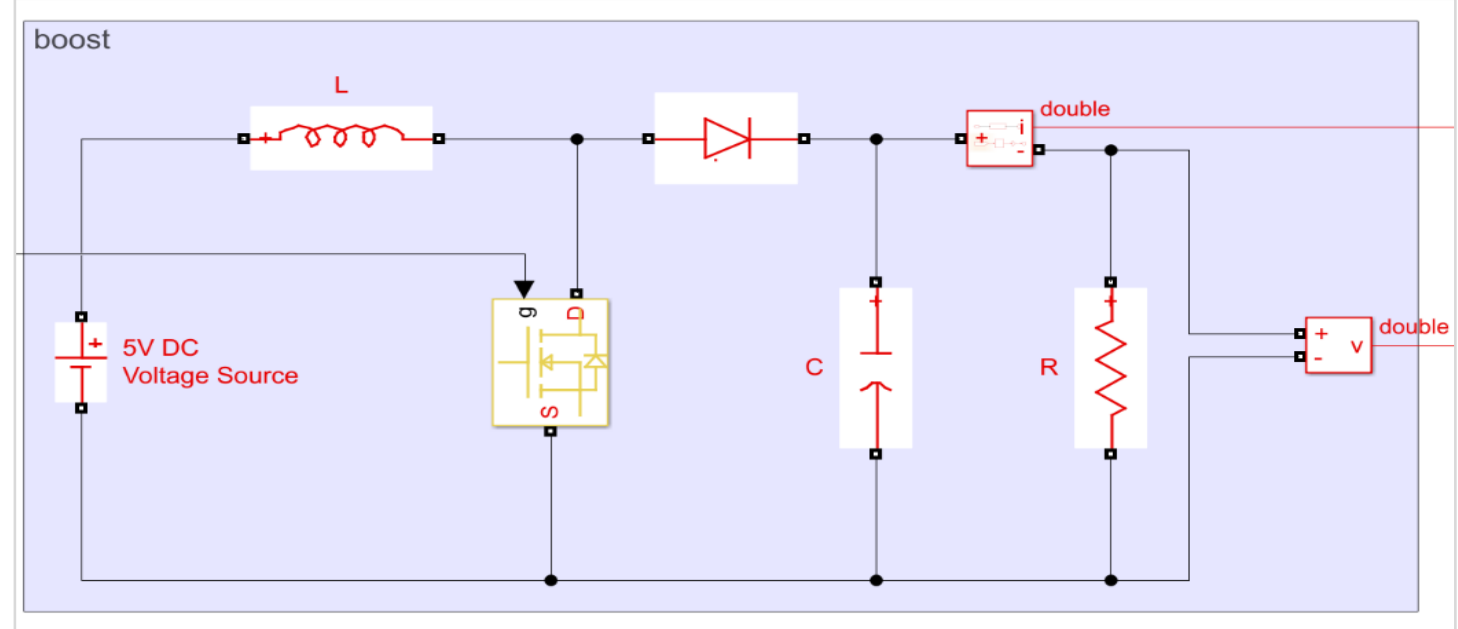

Figure 5 Boost converter submodule 
3.3Digital controller implementation

The digital controller was designed using ModelSim PE Student Edition 10.4a. ModelSim was chosen because the software is compatible and can be integrated with MATLAB/Simulink. The language used is Verilog HDL, where the architecture of the digital controller was generated. Figure $6(a)$ shows the top module for the system.

The top module consists of several submodules, as shown in Figure 6(b). It consists of a counter,
LESSCONSTANT and GREATEROREQUAL. The counter will always count plus one until it reaches LESSCONSTANT set by design. Before it reaches the LESSCONSTANT, the output will always be one, and after that, it will remain zero until the next cycle. However, if there is any signal from duty, the GREATEROREQUAL will be used instead of LESSCONSTANT. For example, if the duty is 50, the counter will count plus one until it reaches 50 and then it turns to 0 .

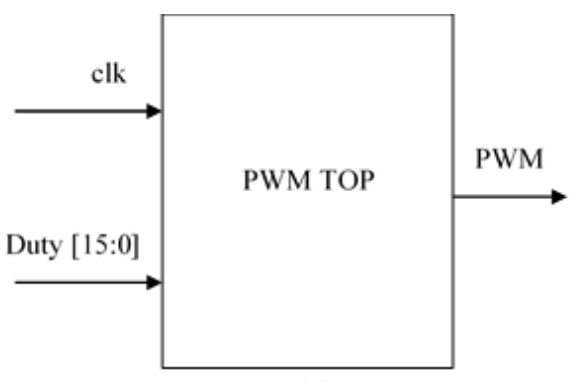

(a)

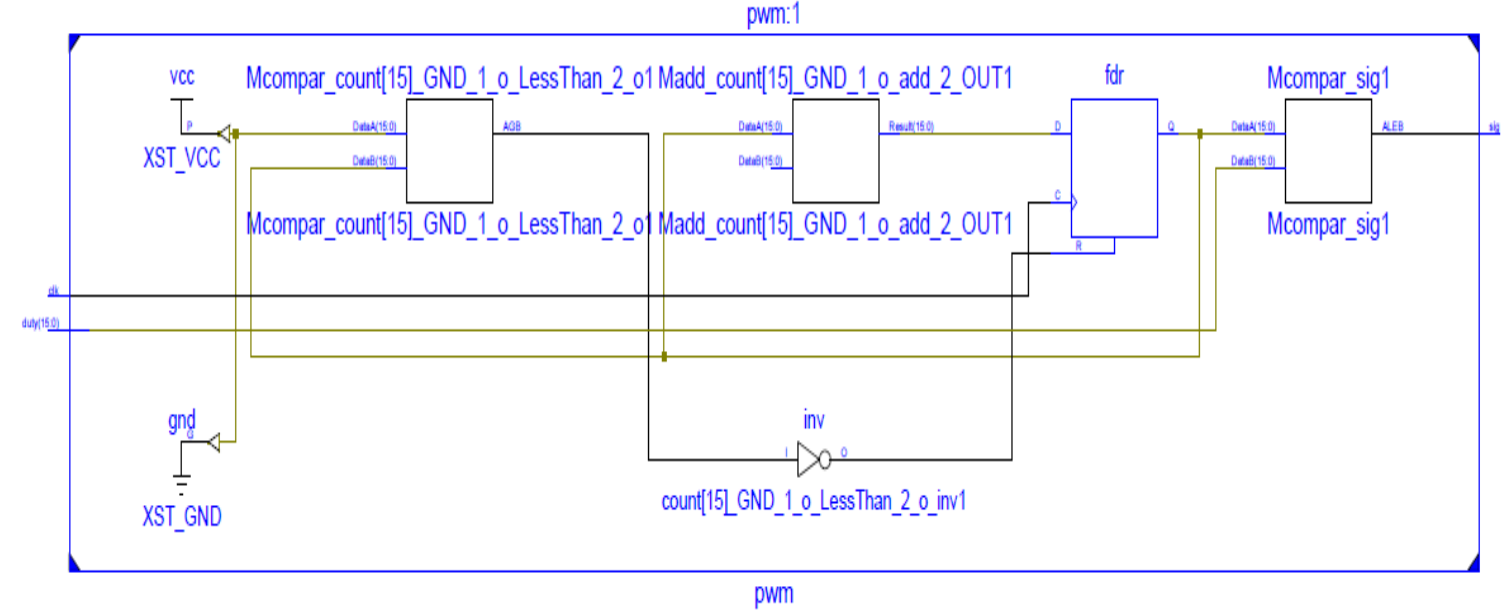

(b)

Figure 6 Digital controller (a) top module (b) submodule

3.4System configuration for digital controller The process for designing Verilog code model is shown in Figure 7. The first step is design entry. Design entry is when source file represent for the design is created. Next is design synthesis where the process development of functional architecture is taken in the functional analysis and allocation step. Both Register-Transfer Level (RTL) and test bench were designed and synthesised in this process. The implementation is done when the simulation result is obtained. 


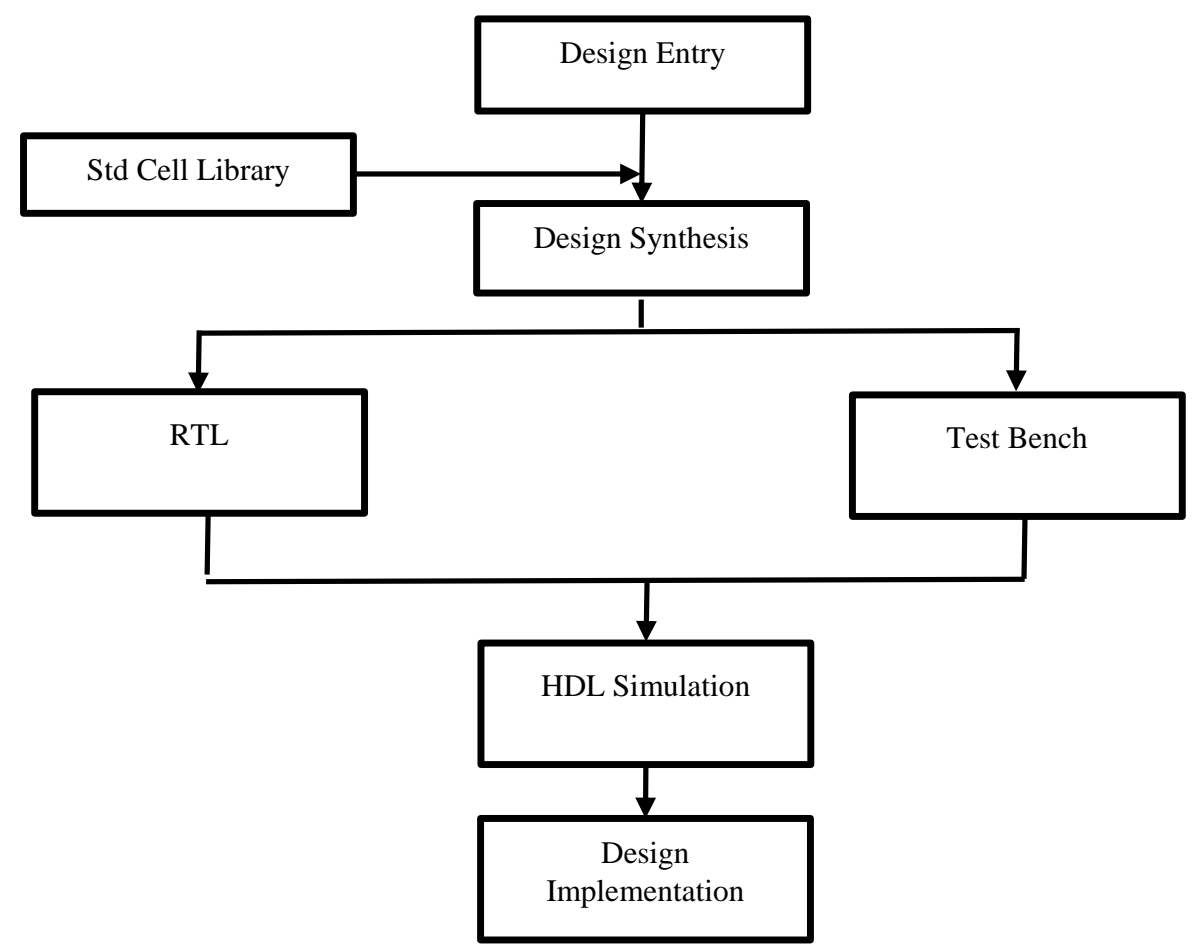

Figure 7 Configuration of digital controller

3.5Verilog implementation into simulink using cosimulation

After verifying the digital controller code in Modelsim, the design was tested with the boost converter system using Simulink co-simulation applications. Co-simulation is a method to integrate data and control flow at the system specification level. Figure 8 shows the overall system with the digital controller designed with the Verilog code. The PWM generator was developed by Modelsim block simulator.

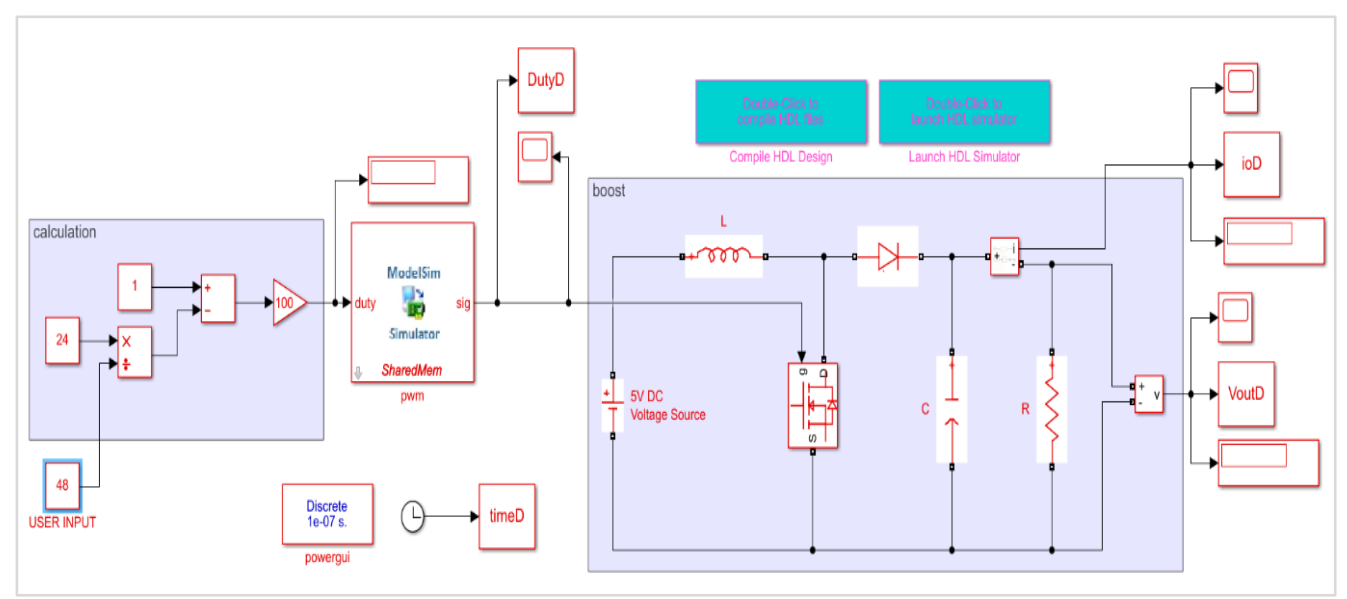

Figure 8 The overall system with digital control

\section{Results}

MATLAB/Simulink was used to simulate the system designed. The results of the output voltage and duty cycle were observed and analyzed. The results were verified based on system performance responses 18 which are rise time (Tr), settling time (Ts) and percent overshoot (\%OS) resulting in under $70 \%$ of the duty cycle. 
4.170\% Duty Cycle- analog controller

Figure 9 shows that the pulse generated by the PWM generator when $70 \%$ of the duty cycle is applied. The frequency used is $20 \mathrm{kHz}$, thus the period cycle will be 50 us. For the $70 \%$ duty cycle, the switch will turn ON for 35 us and turn OFF for 15 us.
Figure 10 shows the input and output voltage when $70 \%$ of the duty cycle is used. From equation (3), the expected output voltage will be $80 \mathrm{~V}$. It is shown that the input voltage is increased from $24 \mathrm{~V}$ to $77.8 \mathrm{~V}$. The graph shows that when $70 \%$ of the duty cycle is applied, the response for voltage and current almost reaches a critically damped response.

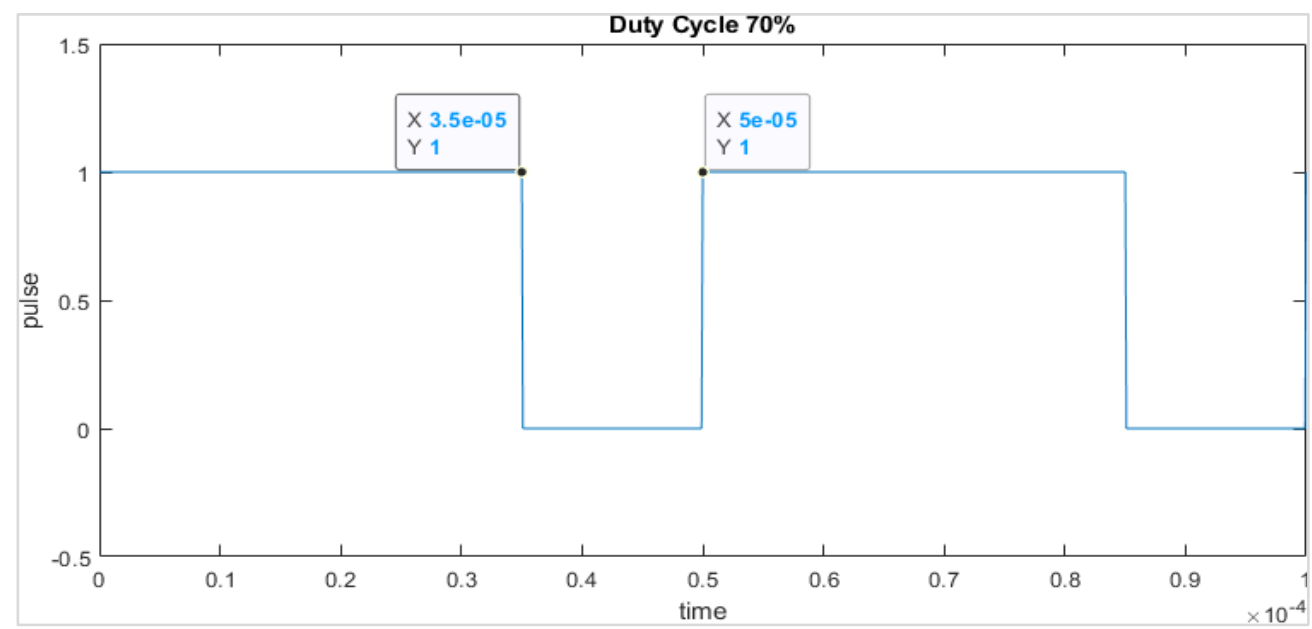

Figure 9 Switching pulse for $70 \%$ of Duty cycle
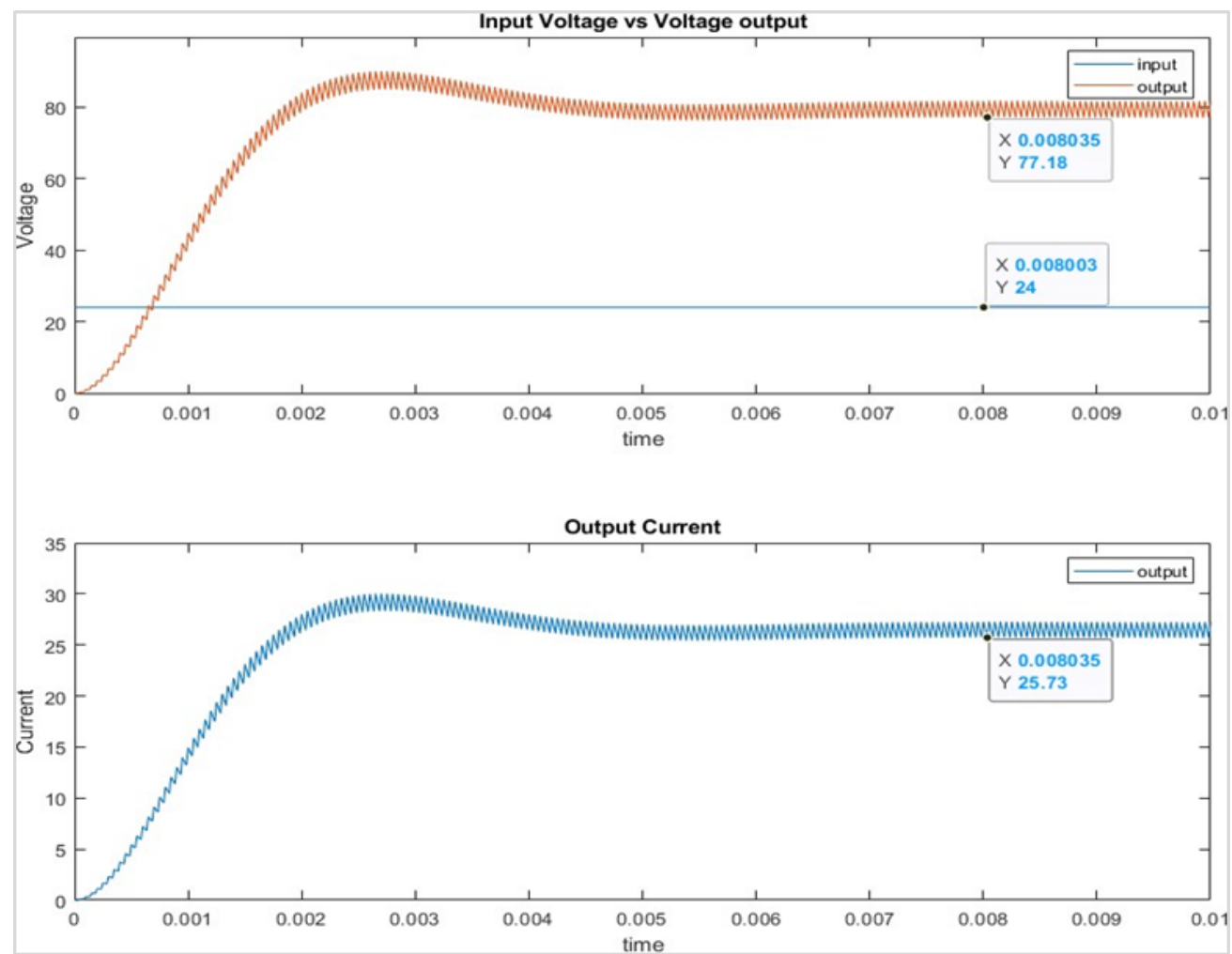

Figure 10 Voltage and current response 
Muaz Zabir bin Mohammad Suhaimi et al.

$4.270 \%$ of duty cycle- digital controller

Figure 11 shows the pulse generated in ModelSim when $70 \%$ of the duty cycle is used. The turn-on mode will be $700 \mathrm{~ns}$ and the turn off mode will be $300 \mathrm{~ns}$.

Figure 12 shows the input and output voltage when $70 \%$ of the duty cycle is used. The expected output voltage will be $80 \mathrm{~V}$. The input voltage has been stepped-up from $24 \mathrm{~V}$ to $79.74 \mathrm{~V}$. From the graph when using $70 \%$ of duty cycle, the boost converter will generate the output signal with nearly critical damping response.

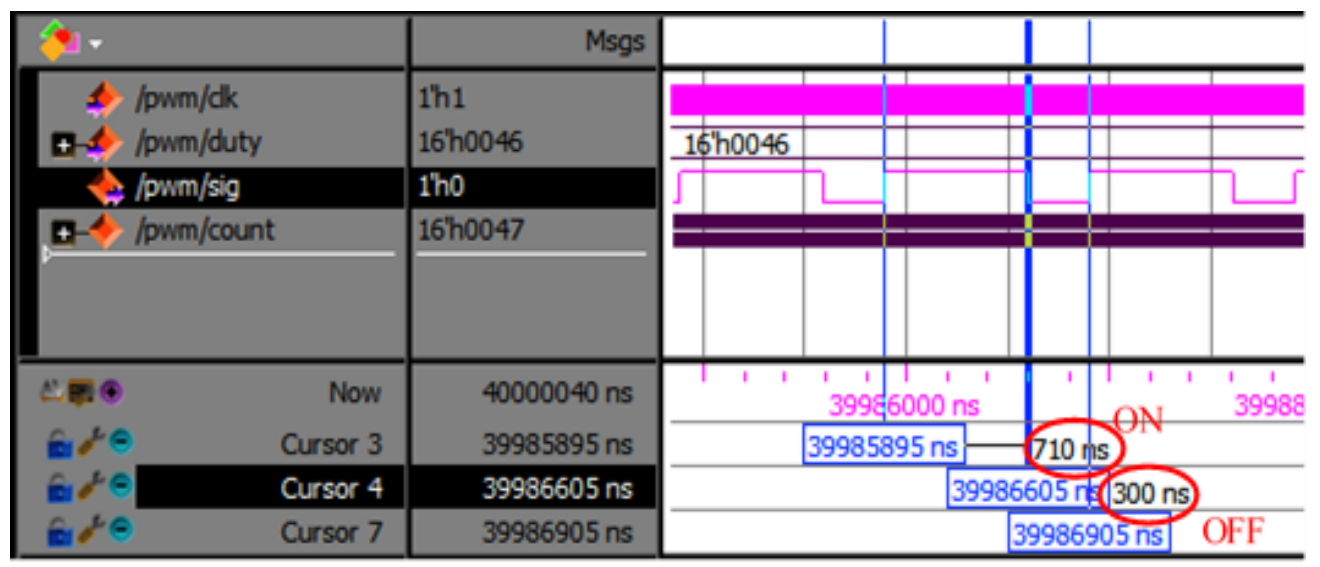

Figure 11 Switching pulse of $70 \%$ duty cycle
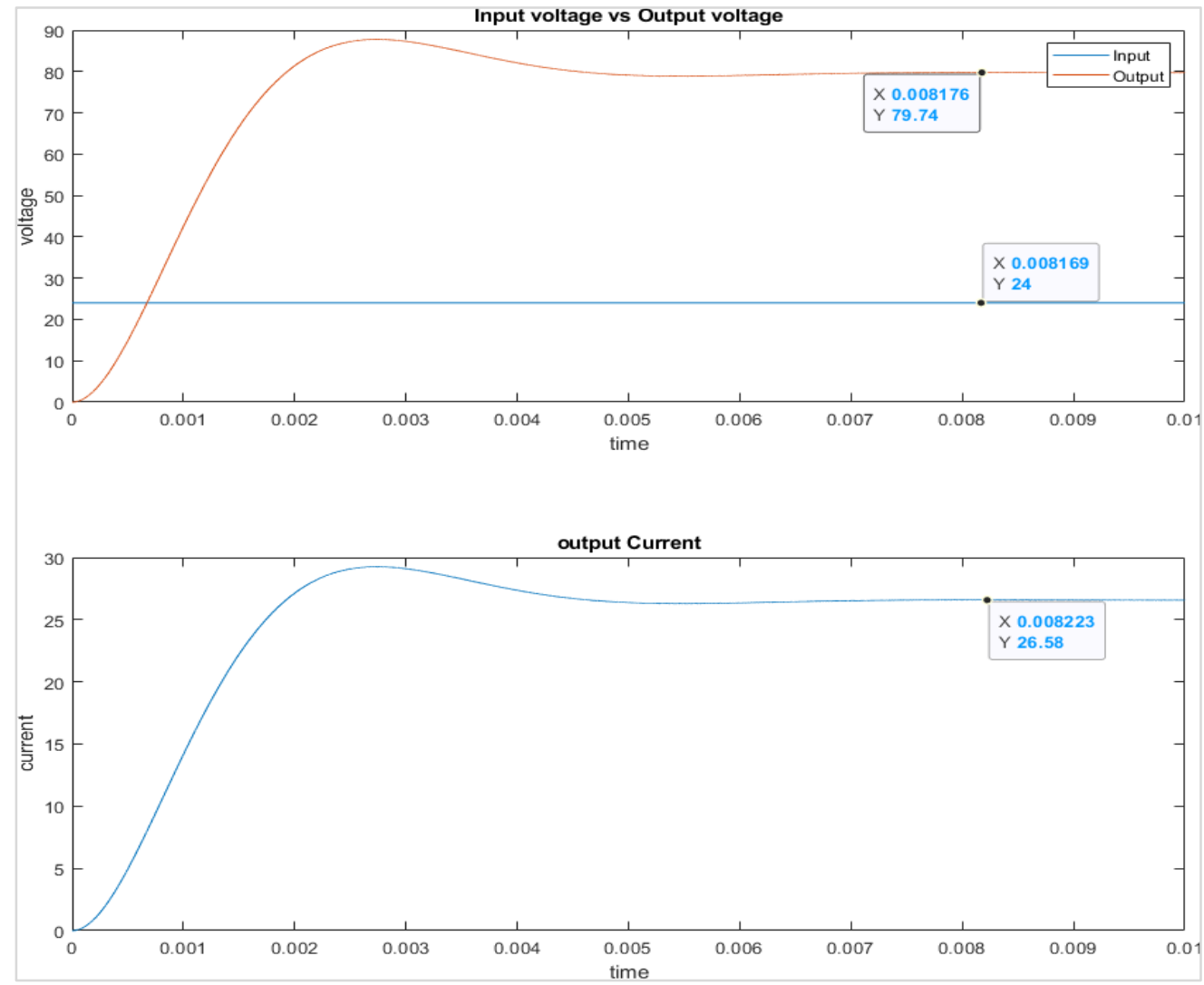

Figure 12 Voltage and current response 


\section{Discussion}

Digital controllers are implemented in a microcontroller or a digital signal processor, while analog control systems are implemented with analog electronics or, eventually, with mechanical parts. Besides that, digital circuits and systems are usually much more robust to noise and inference than the analog circuit. Digital control systems are easily realizable using logic programs and use limited storage space. Also, it takes considerable effort and cost to edit the analog control algorithms, with the change of components. However, digital controllers are easily reprogrammed at no additional cost.

The development of the boost converter based on the mathematical model is constructed using parameters from Table 1. The design was tested and confirmed during the simulation. The simulation for boost converter is done by using MATLAB/Simulink. As depicted in Figure 8, the design is divided into several subsystems to simplify the process flow. The first subsystem will be the calculation process. The sub-system calculation will be received user input for the desired output voltage and automatically calculated the required duty cycle based on equation (3). The duty cycle will be the input for the PWM generator, where it will be produced a pulse signal and injected into the switching device, which is the MOSFET. From here, the boost converter will produce the desired output voltage.

$70 \%$ of the duty cycle is chosen to compare analog and digital controller because both systems show almost critically damped response. Figure 11 shows the digital system's pulse when $70 \%$ of the duty cycle is applied. The Simulink has a function where the time Relate Simulink sample times to the HDL simulation time by specifying a scale factor. A 'tick' is the HDL simulator time resolution. The Simulink sample time multiplied by the scale factor must be a whole number of HDL ticks. Thus, the full period in ModelSim was 1 us. For a $70 \%$ duty cycle, the switch was turned ON for $710 \mathrm{~ns}$ and turned OFF for $300 \mathrm{~ns}$. Noticed that there were $10 \mathrm{~ns}$ different when the switch was turned ON. The digital system needs to consider the timing simulation, where the delay is considered in the process. A 5 ns of delay is added into the system, thus $10 \mathrm{~ns}$ for both edges at turn ON.

The expected output voltage for the boost converter is $80 \mathrm{~V}$. As shown in Figure 10, the output voltage for the analog controller is $77.8 \mathrm{~V}$, while for the digital controller as shown in Figure 12, the output voltage is $79.74 \mathrm{~V}$. The graph shows that when $70 \%$ of duty cycle is applied, the response for voltage almost reaches critically damped response.

Table 2 tabulated the comparison between analog and digital controllers of the system. The duty cycle used is $70 \%$, and from equation (3), the expected voltage for both systems is $80 \mathrm{~V}$. For the digital system, the output generated was $79.74 \mathrm{~V}$ with only $0.325 \%$ error. In comparison, the analog system produced an output voltage of $81.7 \mathrm{~V}$, which has a $2.125 \%$ of error. For rise time, Tr, both systems had the same time taken at $0.0013 \mathrm{~s}$. However, for settling time, Ts, the digital system has taken half of the time used by analog at $0.0042 \mathrm{~s}$. Digital system also has lower overshoot than analog, which is $10.1228 \%$. For voltage ripple, the digital system also has a lower value at $0.1093 \%$ compared to analog at $5.822 \%$. Digital system also has lower overshoot than analog, which is $10.1228 \%$. For voltage ripple, the digital system also has a lower value at $0.1093 \%$ compared to analog at $5.822 \%$. The result shows that the digital controller gives a better performance of boost converter than the analog controller.

Table 2 Data comparison between analog and digital system

\begin{tabular}{lll}
\hline & Analog & Digital \\
\hline Vout (expected) & $80 \mathrm{~V}$ & $80 \mathrm{~V}$ \\
\hline Vout (actual) & $81.7 \mathrm{~V}$ & $79.74 \mathrm{~V}$ \\
\hline$\%$ error $(\%)$ & 2.125 & 0.325 \\
\hline Tr(s) & 0.0013 & 0.0013 \\
\hline Ts $(\mathrm{s})$ & 0.0100 & 0.0042 \\
\hline Overshoot $(\%)$ & 10.2738 & 10.1228 \\
\hline Voltage Ripple $(\%)$ & 5.822 & 0.1093 \\
\hline
\end{tabular}

\section{Conclusion and future work}

Among these two systems, digital control was producing good performance compared to the analog system. The duty cycle that produces the best response is $70 \%$, resulting in a near-critical damping response. The result shows that with the same circuit configuration for boost converter, the digital system can produce more precise output compared to the 
analog system with under $1 \%$ of error. The digital system can also reach settling time faster and has a lower ripple factor at a result. In the future, the digital controller design can be modified with better performance and accuracy. The design should be able to implement in the closed-loop system, therefore increasing the accuracy.

\section{Acknowledgment}

The authors gratefully acknowledge Universiti Teknologi MARA, Cawangan Pulau Pinang and Faculty of Electrical Engineering for the facility to complete this project and the support.

\section{Conflicts of interest}

The authors have no conflicts of interest to declare.

\section{References}

[1] Channappanavar R, Mishra S. A review of compensator design for digital controller implementation for DC-DC converters. In energy conversion congress and exposition 2018 (pp. 1401-6). IEEE.

[2] Shousha M, Prodić A, Marten V, Milios J. Design and implementation of assisting converter-based integrated battery management system for electromobility applications. IEEE Journal of Emerging and Selected Topics in Power Electronics. 2017; 6(2):825-42.

[3] Huynh PS, Vincent D, Patnaik L, Williamson SS. FPGA-Based PWM implementation of matrix converter in inductive wireless power transfer systems. In PELS workshop on emerging technologies: wireless power transfer 2018 (pp. 1-6). IEEE.

[4] Tran DD, Geury T, El Baghdadi M, Van Mierlo J, Hegazy O. Design and implementation of FPGAbased digital controllers for $\mathrm{SiC}$ multiport converter in electric vehicle drivetrains. In 21st European conference on power electronics and applications 2019 (pp. 1-11). IEEE.

[5] Zhang N, Sutanto D, Muttaqi KM. A review of topologies of three-port DC-DC converters for the integration of renewable energy and energy storage system. Renewable and Sustainable Energy Reviews. 2016; 56:388-401.

[6] Azman MA, Aris JM, Hussain Z, Samat AA, Nazelan AM. A comparative study of fuzzy logic controller and artificial neural network in speed control of separately excited DC motor. In international conference on control system, computing and engineering 2017 (pp. 336-41). IEEE.

[7] Liu J, Liu M, Pei D, Sun H. FPGA implementation of family service robot based on neural network PID motion control system. In international conference on electronic engineering and informatics 2019 (pp. 3048). IEEE.

[8] Chen Y, Xie F, Zhang B, Qiu D, Xu M. Analysis of digital PCM-controlled boost converter with trailingedge modulation based on $\mathrm{z}$-domain and describing- function model. IEEE Journal of Emerging and Selected Topics in Power Electronics. 2020; 8(4):3250-9.

[9] Sharma K, Palwalia DK. Design of digital PID controller for voltage mode control of DC-DC converters. In international conference on microelectronic devices, circuits and systems 2017 (pp. 1-6). IEEE.

[10] Forcan M, Maksimović M. Cloud-fog-based approach for smart grid monitoring. Simulation Modelling Practice and Theory. 2020; 101:1-18.

[11] Qin Y, Yang Y, Li S, Huang Y, Tan SC, Hui SY. A high-efficiency DC/DC converter for high-voltagegain, high-current applications. IEEE Journal of Emerging and Selected Topics in Power Electronics. 2019; 8(3):2812-23

[12] Guerrero E, Guzmán E, Linares J, Martínez A, Guerrero G. FPGA-based active disturbance rejection velocity control for a parallel DC/DC buck converterDC motor system. IET Power Electronics. 2019; 13(2):356-67.

[13] Patel J, Sood VK. Review of digital controllers in power converters. In electrical power and energy conference 2018 (pp. 1-8). IEEE.

[14] Chenchireddy K, Jegathesan V, Kumar LA. Different topologies of inverter: a literature survey. Innovations in Electrical and Electronics Engineering. 2020:35-43.

[15] Lupon E, Busquets-Monge S, Nicolas-Apruzzese J. FPGA implementation of a PWM for a three-phase DC-AC multilevel active-clamped converter. IEEE Transactions on Industrial Informatics. 2014; 10(2):1296-306.

[16] Khiavi AM, Sobhi J, Koozehkanani ZD, Kangarlu MF. FPGA-based reconfigurable PWM generator for power electronic converter applications. Journal of Control, Automation and Electrical Systems. 2017; 28(4):516-31.

[17] Milanovic M, Truntic M, Slibar P. FPGA implementation of digital controller for DC-DC buck converter. In fifth international workshop on systemon-chip for real-time applications 2005 (pp. 439-43). IEEE.

[18] Chithra S, Maheswaran VD. Design and implementation of modern digital controller for DCDC converters. International Journal of Advanced Research in Electrical, Electronics and Instrumentation Engineering (An ISO 3297: 2007 Certified Organization). 2014.

[19] Schkufza E, Wei M, Rossbach CJ. Just-in-time compilation for verilog. In architectural support for programming languages and operating systems. 2019(pp. 1-13).

[20] Chen HC, Chen TH, Li CY. Modeling and control for interleaved voltage-doubler boost converter. In energy conversion congress and exposition 2018 (pp. 168-74). IEEE.

[21] Monmasson E, Cirstea MN. FPGA design methodology for industrial control systems - a review. IEEE Transactions on Industrial Electronics. 2007; 54(4):1824-42. 


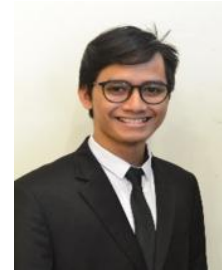

Muaz Zabir bin Mohammad Suhaimi received a Bachelor degree in Electrical and Electronic Engineering in 2020 from Universiti technologi Mara (UiTM). Currently he is working as graduate engineer at Intel which specialize in design testing.

Email: muazzabir12@gmail.com

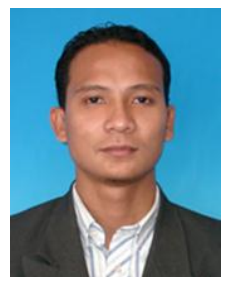

Ahmad Asri Abd Samat received a BSc. (Hons) Electrical and Electronic Engineering from MARA University of Technology, Malaysia and M. Eng (Electrical Energy and Power System from University of Malaya, Malaysia in 2004 and 2006, respectively. In 2019, he finished his $\mathrm{PhD}$ in the field of Electrical Machines and Drives from Universiti Sains Malaysia, Malaysia. Now, he is a Senior Lecturer in Electrical Engineering at the Faculty of Electrical Engineering, Universiti Teknologi MARA, Permatang Pauh Penang, Malaysia. He is looking forward to explore new area of research and collaborations with other parties. Email: ahmadasri759@uitm.edu.my

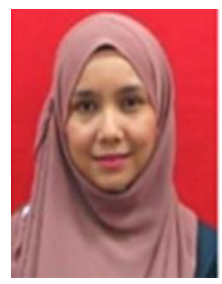

Nor Salwa Damanhuri received her B.Sc. (Hons) in Electrical \& Electronics Engineering from Universiti Tenaga Nasional (UNITEN) Malaysia. In 2004, she received the Excellence Scheme Programme from MARA to pursue her MSc. in Control Systems Engineering in University of Sheffield, United Kingdom. She spent 4 years working as a Product Engineer in Freescale Semiconductor Malaysia (fka Motorola Semiconductor) before embarking her journey as a lecturer at the Universiti Teknologi MARA (UiTM) Pulau Pinang. She obtained her $\mathrm{PhD}$ in Bioengineering from University of Canterbury, New Zealand in 2015. Currently, she holds a position as a senior lecturer in Faculty of Electrical Engineering, UiTM Pulau Pinang. Her research interests include lung Mechanics Modelling, System Identification Methods, Modelling for type 2 Diabetic Patients and Solar PV System.

Email: norsalwa071@uitm.edu.my

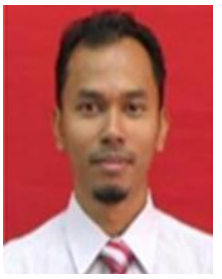

Nor Azlan Othman received her B.Sc. (Hons) in Electrical \& Electronics Engineering from Universiti Tenaga Nasional (UNITEN) Malaysia. In 2004, he received the Excellence Scheme Programme from MARA to pursue his MSc. in Control Systems Engineering in University of Sheffield, United Kingdom. He had several years of experiences as a R\&D Engineer in Sony and Motorola Malaysia. He obtained his $\mathrm{PhD}$ in Bioengineering from University of Canterbury, New Zealand in 2015. Currently, he is a senior lecturer in Faculty of Electrical Engineering, UiTM Pulau Pinang. His research interests include Physiological Modelling, Parameter Identification, Insulin Sensitivity for type 2 Diabetes, Renewable Energy and Control Systems.

Email: azlan253@uitm.edu.my

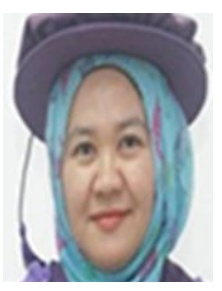

Irni Hamiza Hamzah was born in Machang, Kelantan on 6th December 1974. She obtained her B. Eng (Hons) in Electrical and Electronic Engineering in 1998, MSc. Electronics System and Design Engineering in 2005 and $\mathrm{PhD}$ in BioMEMs Sensors in 2013, which all had been obtained from School of of Electrical and Electronic Engineering, Universiti Sains Malaysia, Malaysia. She is currently a Senior Lecturer in Electronic Engineering Department, Faculty of Electrical Engineering, Universiti Teknologi MARA, Penang Branch Campus, Malaysia. Her research interests include Biosensors, BioMEMs, Neural Networks and Renewable Energy. She is a registered Board of Engineers Malaysia (BEM) Professional Engineer.

Email: irnihami@uitm.edu.my

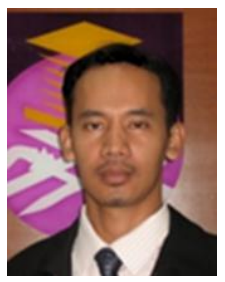

Mohd Hanapiah Abdullah received a BSc. (Hons) Electrical and Electronic Engineering from MARA University of Technology, Malaysia and M. Sc (Microelectronics) in the field of Optoelectronics from University of UKM, Malaysia in 2000 and 2005, respectively. In 2015, he finished his $\mathrm{PhD}$ in the field of Nanotechnology Device Fabrication for Green Technology from UiTM, Shah Alam, Malaysia. Now, he is a Senior Lecturer in Electronic Engineering at the School of Electronics, Faculty of Electrical Engineering, Universiti Teknologi MARA, Permatang Pauh Penang, Malaysia. $\mathrm{He}$ is a member of the NanoElectronic Center (NET), Innovation Center (IOS), UiTM Shah Alam. He is looking forward to explore new area of research and collaborations with other parties. Email: hanapiah801@uitm.edu.my 